\title{
GENERAL BIOCHEMICAL DERANGEMENT RELATED TO THE USE OF STATINS IN THE TREATMENT OF FAMILIAL HYPERCHOLESTEROLEMIA.
}



Correspondence Address: Dr. Sufyan Tahir

Department of Pathology Army Medical College/

Military Hospital Rawalpindi, Pakistan. dr.sufyan83@gmail.com

Article received on: 21/05/2019

Accepted for publication: $15 / 10 / 2019$

\section{Sufyan Tahir ${ }^{1}$, Muhammad Usman ${ }^{2}$, Hafiza Seerat Fatima ${ }^{3}$}

ABSTRACT... Objectives: This study was carried out to evaluate the patients of familial hypercholesterolemia (FH) on statin therapy for general biochemical abnormalities. Study Design: Case-Control observational study. Setting: Department of Chemical Pathology (Army Medical College/Military Hospital Rawalpindi) in collaboration with center for research in experimental and applied medicine (CREAM lab). Periods: From Jan 2017 to Jan 2018. Material \& Methods: A total of one hundred participants were recruited in this study. These hundred cases were further divided into two groups. First group comprised of fifty disease free healthy cases, while the second group included the patients of familial hypercholesterolemia diagnosed on the basis of Simon Broom criteria. This second group was categorized into further two groups on the basis of patients taking statin therapy or not. Fasting blood sample was taken from these cases complete blood count, liver function tests, fasting plasma glucose, glycosylated hemoglobin, lipid profile and renal function tests were performed on these blood samples and the results were compared to find out any biochemical variance in control and cases. Results of this study were analyzed on SPSS v.23. Results: The analysis of lipid profile including total cholesterol (T.Ch), triglycerides (TRG), low-density lipoprotein cholesterol (LDL-C) and high density cholesterol (HDL-C) showed a highly significant difference in cases and controls. Alanine aminotransferease (ALT), alkaline phosphatase (ALP) and bilirubin also showed a significant variation. While diabetic profile, urea, creatinine, hemoglobin and body mass index didn't show any significant variation among cases and controls. Conclusion: It is well-known that statins prove to be more superior to other classes of anti-hyperlipidemic, but at same time use of statins are also associated with other biochemical derangements. Diabetes mellitus is one of them. Therefore, a close monitoring protocol is required during statin therapy.

Key words: Biochemical Markers, Familial Hypercholesterolemia, Glycosylated Hemoglobin, Lipid Profile, Liver Function Tests, Renal Function Tests, Thyroid Stimulating Hormone.

Article Citation: Tahir S, Usman M, Fatima HS. General biochemical derangement related to the use of Statins in the treatment of Familial Hypercholesterolemia. Professional Med J 2020; 27(1):132-137.

DOI: $10.29309 / T P M J / 2020.27 .1 .3743$

\section{INTRODUCTION}

Familial hypercholesterolemia is a genetic disorder of autosomal dominant variety ${ }^{1}$ and it is characterized by abnormally elevated low density lipoprotein cholesterol. Its physical manifestations are in the form of xanthomas, arcus cornea and premature coronary vascular disease i.e. myocardial infarction, narrowing of the arteries or problems occurring in heart valves $^{2}$ Notably xanthomas can be found in the extensor tendons, metacrpo-phalangeal joints or anywhere in the skin. It is the most common gene variable which can cause pre-mature mortality and morbidity. ${ }^{3}$ As a separate clinical identity this disease is well known for more than a century, but its genetic predispositions came under the scope in the past three decades. ${ }^{4}$ Three major mutations in different genes are discovered recently which are responsible for causing this disease. These include low density lipoprotein receptor gene mutation (the most prevalent), Apo-B gene mutation and proprotein convertase subtilisin kexin type 9 or PCSK9 (the rarest). ${ }^{5}$ This disease is the result of single gene defect or the additive effect of genetic mutation and environmental stresses. The prevalence of 
familial hypercholesterolemia is documented to 1 in 500 individuals. Heterozygous familial hypercholesterolemia (HeFH) is the commonest and homozygous familial hypercholesterolemia $(\mathrm{HoFH})$ is the rarest. ${ }^{6}$

For the treatment of $\mathrm{FH}$, different options are present for preserving the quality of life style. In 2001 NCEP ATPIII guidelines has surfaced a multifaceted approach for the prevention of coronary artery disease in the patients of hypercholesterolemia. These includes a designated therapeutic life style changes, in which the recommended daily allowance of fibers, carbohydrates, fats (Saturated and un-saturated) etc is defined with the recommendations of daily exercises. ${ }^{7}$ Despite of the advancement of new treatment modalities in this disease, the main aim is still to keep the levels of total cholesterol and low-density lipoprotein cholesterol in desirable range. In order of achieving it still statins are the drug used widely despite of a higher prevalence of its adverse effects. Especially in the developing countries like Pakistan where the concept of diagnostic modalities like molecular genetic testing for the confirmation of different diseases is still a new concept. The effects of statins in preventing of cardiovascular disease is probably more than that of its lipid lowering capacities. Despite of the fact that statins are highly tolerable class of medicine, the debate on adverse effects of statins is still on. Different meta-analysis and consensus working group have shown adverse effects of statins out-ranked its beneficial effects. ${ }^{8}$ These Meta analyses have also deemed different treatment and preventive therapies in lowering the possible side effects of statins. These include myalgia, arthralgia, new onset diabetes mellitus, elevated liver enzymes, cataract and cerebrovascular accidents. ${ }^{9}$

\section{MATERIAL \& METHODS}

The study was conducted in the Chemical Pathology department Army medical college/ Military hospital Rawalpindi, after obtaining the approval from the ethical review committee of the institute. The duration of this study is one year from Jan 2017 to Jan, 2018. Total number of cases were 100. Non probability purposive sampling technique was used for this case control observational study. These 100 cases were further divided into two groups. Group A comprised of disease-free healthy individuals having normal lipid profile Cholesterol< $5.20 \mathrm{mmol} / \mathrm{l}$, while group $B$ is further divided into two sub-groups. Group B-1 comprised of diagnosed cases of familial hypercholesterolemia Cholesterol $>5.20$ $\mathrm{mmol} / \mathrm{l}$ using statins. While group B-2 were the recently diagnosed cases of $\mathrm{FH}$ and not on statin therapy. The purpose and procedure of the study was explained to each individual and their written consent was taken. The anonymity of every participant was strictly assured.

The age, gender, height, weight, demographics and socioeconomic data was collected for each of the participant of the study. A total of $5 \mathrm{ml}$ of fasting venous blood was taken. $2.5 \mathrm{ml}$ was taken in a plain tube, $1.5 \mathrm{ml}$ was taken in EDTA tube and 1 $\mathrm{ml}$ was taken in the tube containing NaF (Sodium Flouride). Serum was separated by centrifuging the blood at 4500 RPM for 5 minutes. Complete blood count and $\mathrm{HbA1C}$ were performed on the blood collected in EDTA tube. Flow cytometry (Sysmex) was used for CBC analysis and immunenephelometry (Diasys Responc 910) was used for determination of $\mathrm{HbA1c}$. Fasting plasma glucose level was performed on the tube containing sodium fluoride. Routine chemical analysis including liver function tests, renal function tests and lipid profile were performed on the serum separated from the plain tube. These assays were performed on Selectra (Spectrophotometer principle). Thyroid stimulating hormone was also measured using immunoassay technique. Statistical package for social sciences (SPSS) v. 23 and Microsoft Excel were used for the statistical analysis. The mean, average and standard deviation of all the three groups was calculated. Test of significance (ANOVA) was applied to all the analytes performed on the groups to check the variation among the mean of these three groups.

\section{RESULTS}

A total of 100 individuals were selected for the study. Fifty of these were the cases and 50 of these were the controls. All the cases were the patients of familial hypercholesterolemia diagnosed on the 
basis of Simon Broom criteria. These cases were divided into two groups, group B-1 (Yes) using statins and group B-2 (No) not on statin therapy.



Figure-1. Segregation according to gender, cases and controls.

Anthropometric data in the three groups was measured and then analyzed on the basis of mean and standard deviation. The comparison of age, weight, height and body mass index is shown in the following Table-I.

General biochemistry including fasting plasma glucose, lipid profile, renal function tests, liver function tests and thyroid stimulating hormones were measured and analysed for three groups. The results showed that glycosylated haemoglobin, thyroid stimulating hormone and creatinine were the analytes among three groups which did not show any significant variation i.e (>.05) by applying ANOVA (Analysis of variance) Table-Il.

On the other hand, Hb levels, urea, cholesterol, triglyceride, low density lipoprotein cholesterol, high density lipoprotein cholesterol, alanine aminotransferase, alkaline phosphatse, bilirubin and plama glucose levels showed a significant variation among their means i.e $(<.05)$.

\begin{tabular}{|l|c|c|c|}
\hline & \multicolumn{2}{|c|}{ Case } & Control \\
\cline { 2 - 4 } & Statin user (B-1) & Non-statin user(B-2) & $29.0+12.93$ \\
\hline Age (Years) & $19.39+15.35$ & $20.61+19.63$ & $58.81+16.85$ \\
\hline Weight $(\mathrm{Kg})$ & $38.84+19.33$ & $37.03+26.51$ & $156.94+23.03$ \\
\hline Height $(\mathrm{Cm})$ & $128.5+25.13$ & $122.06+40.89$ & $23.18+3.38$ \\
\hline BMI $(\mathrm{Kg} / \mathrm{m} 2)$ & $21.76+4.21$ & $21.27+3.55$ & 2 \\
\hline
\end{tabular}

Table-I. Comparison of anthropometric data.

\begin{tabular}{|c|c|c|c|c|}
\hline & \multicolumn{2}{|c|}{ Case } & \multirow{2}{*}{ Control } & \multirow{2}{*}{ P-Value } \\
\hline & Group B-1 & Group B-2 & & \\
\hline Hb Level (g/dl) & $11.5+2.18$ & $11.8+2.76$ & $13.18+1.82$ & 0.002 \\
\hline Creatinine $(\mu \mathrm{mol} / \mathrm{L})$ & $62.78+14.54$ & $62.28+28.75$ & $70.28+11.02$ & 0.072 \\
\hline $\mathrm{HbA1C}$ & $5.1+0.59$ & $4.9+0.71$ & $5.17+0.56$ & 0.267 \\
\hline Triglyceride(mmol/L) & $2.11+1.55$ & $2.84+2.54$ & $1.32+0.42$ & 0.000 \\
\hline LDL $(\mathrm{mmol} / \mathrm{l})$ & $12.28+5.91$ & $6.99+5.3$ & $2.25+0.5$ & 0.000 \\
\hline $\mathrm{HDL}(\mathrm{mmol} / \mathrm{L})$ & $2.01+0.65$ & $1.3+0.69$ & $0.99+0.18$ & 0.000 \\
\hline $\mathrm{TSH}(\mathrm{mlU} / \mathrm{L})$ & $2.03+1.36$ & $2.12+0.89$ & $1.69+0.88$ & 0.221 \\
\hline $\mathrm{FPG}(\mathrm{mmol} / \mathrm{L})$ & $4.97+0.66$ & $4.34+0.86$ & $5.04+0.92$ & 0.010 \\
\hline Hb Level (g/dl) & $11.5+2.18$ & $11.8+2.76$ & $13.18+1.82$ & 0.002 \\
\hline & & Table-II. & & \\
\hline
\end{tabular}


Furthermore to analyze the significance among the cases and controls and also among the two sub-groups of cases post-hoc Tuckey test was applied, which showed that haemoglobin levels are markedly low in group B-1 (statin users ) as compared to group A and group B-2. Urea showed a significant variation in the patients of familial hyperchlorestrolemia (whether statin users or statin non-users) as compared to the controls. Cholesterol, triglyceride, LDL-C and HDL-C also showed a significant variation between all three groups due to selection criteria (except triglycerides in controls and statin users and HDL-C in controls and non-statin user). ALT showed a significant variation in the patients of $\mathrm{FH}$ having statins as compared to the controls, while our results didn't show any significant variation between the statin users and non-statin users. Alkaline phosphatase is markedly significant for both the statin and non-users as compared to controls. Fasting plasma glucose was found to be non-significant among the two sub groups of cases and also for the controls and statin users, while it showed a significant variation for in the controls and non users of statins. Fasting plasma glucose showed significant variation for the statin users as compared to non statin users and also for the non-statin users and control. But when compared between controls and non statin users it didn't show any significant variation. Table-III

\begin{tabular}{|c|c|c|c|}
\hline \multirow{3}{*}{ Hb Level } & Yes & No & 0.886 \\
\hline & Control & Yes & 0.002 \\
\hline & Control & No & 0.053 \\
\hline \multirow{3}{*}{ Urea } & Yes & No & 0.351 \\
\hline & Control & Yes & 0.005 \\
\hline & Control & No & 0.000 \\
\hline \multirow{3}{*}{ Cholesterol } & Yes & No & 0.000 \\
\hline & Control & Yes & 0.000 \\
\hline & Control & No & 0.000 \\
\hline \multirow{3}{*}{ Triglyceride } & Yes & No & 0.190 \\
\hline & Control & Yes & 0.040 \\
\hline & Control & No & 0.000 \\
\hline \multirow{3}{*}{ LDL } & Yes & No & 0.000 \\
\hline & Control & Yes & 0.000 \\
\hline & Control & No & 0.000 \\
\hline \multirow{3}{*}{$\mathrm{HDL}$} & Yes & No & 0.000 \\
\hline & Control & Yes & 0.000 \\
\hline & Control & No & 0.058 \\
\hline \multirow{3}{*}{ Biliribuin } & Yes & No & 0.171 \\
\hline & Control & Yes & 0.254 \\
\hline & Control & No & 0.004 \\
\hline \multirow{3}{*}{ ALT } & Yes & No & 0.986 \\
\hline & Control & Yes & 0.039 \\
\hline & Control & No & 0.153 \\
\hline \multirow{3}{*}{ ALP } & Yes & No & 0.022 \\
\hline & Control & Yes & 0.000 \\
\hline & Control & No & 0.000 \\
\hline \multirow{3}{*}{ FPG } & Yes & No & 0.031 \\
\hline & Control & Yes & 0.939 \\
\hline & Control & No & 0.009 \\
\hline
\end{tabular}

Table-III. Intergroup comparison of Biochemical variables. 


\section{DISCUSSION}

Hyperchloretrolemia is a risk factor of cornoary vascular disease by systemic atherosclerosis under the influence of platelets aggregation and low density lipoprotein cholesterol rich particles which can be found in atherosclerotic plaques. ${ }^{10,11}$ The cholesterol present in the cell membrane is responsible for the fluidity, bending and tensile strength. The deformaty in the red cell membrane are ATP dependent. So one of the underlying mechanism which describes the anti-thrombotic mechanism of statins also showed the decrease in cholesterol in the membrane of red cell, causing a deformity and also decrease in the aggregation of red blood cells, thus decrease in the mean carpuscular volume and haemoglobin. ${ }^{12}$ Statin use provides an excellent cover against the CVD but at the same time there is an increased prevalence of type II DM in the statin users. Kenneth et al showed in a study that $7.2 \%$ out of $12.6 \%$ of the research participants, who have started statin therapy, developed diabetes mellitus..$^{13}$ Our study has also showed a significant variation of fasting plasma between statin users and non-users. The urea also showed a significant variation between controls and statin users and also between control and non-statin users. It is an established fact that the statin induces insulin resistance in the long run is responsible for causing diabetes mellitus and also nephropathy which leads to derranged renal functions of the patient. ${ }^{14}$ The significance between the controls and non-statin users are due to the fact that these are newly diagnosed cases of familial hyperchlorestrolemia. Mostly these study participant fall under pediatric age group. The range of urea in this group is lower than the adult age group which leads to a significant variance of between controls and nonstatin users. ${ }^{15}$

Statins are responsible for blocking HMGCoA pathway in the liver. Occasionally statin use is related to higher levels of liver enzymes namely alanine amino transferase and alkalaine phosphatase. The increase in these enzyme can effect the efficacy of the statin therapy. ${ }^{16}$ Our study has also showed a significant variation of ALT and AIP in the statin users as compared to control. The lipid profile including cholesterol, triglyceride, high density lipoprotein cholesterol and low density lipoprotein cholesterol all showed a significant variation between the controls and cases due to the selection criteria. Patients are selected as per Simon Broom criteria of definate familial hypercholestrolemia which states a level of total cholesterol more than $7.5 \mathrm{mmol} / \mathrm{I}^{17}$

\section{CONCLUSION}

Statin use in the patients of hyperlipidemia is related to different biochemical derrangements. Diabetes mellitus can be the worst outcome related to statin use. But at the same time statins have proved their efficacy against incident of premature coronary artery mortility and morbidity. Its benefit definitely out shines the risk. Following a close monitoring protocol statins prove to be more superior than other classes of antihyperlipidemic.

Copyright $\odot 15$ Oct, 2019.

\section{REFERENCES}

1. Santos RD, Gidding SS, Hegele RA, Cuchel MA, Barter PJ, Watts GF, et al. Defining severe familial hypercholesterolaemia and the implications for clinical management: A consensus statement from the International Atherosclerosis Society Severe Familial Hypercholesterolemia Panel. The lancet Diabetes \& endocrinology. 2016; 4(10):850-61.

2. Mastrolorenzo A, D'Errico A, Pierotti P, Vannucchi M, Giannini S, Fossi F. Pleomorphic cutaneous xanthomas disclosing homozygous familial hypercholesterolemia. World Journal of Dermatology. 2017; 6(4):59-65.doi: 10.5314/wjd.v6.i4.59

3. Gidding SS, Champagne MA, de Ferranti SD, Defesche $\mathrm{J}$, Ito MK, Knowles JW, et al. The agenda for familial hypercholesterolemia. Circulation. 2015; 132(22):216792. DOI: $10.1161 /$ CIR.0000000000000297.

4. Khera AV, Won H-H, Peloso GM, Lawson KS, Bartz TM, Deng $X$, et al. Diagnostic yield and clinical utility of sequencing familial hypercholesterolemia genes in patients with severe hypercholesterolemia. Journal of the American College of Cardiology. 2016; 67(22):2578-89. DOI: 10.1016/j.jacc. 2016.03.520

5. Futema M, Shah S, Cooper JA, Li K, Whittall RA, Sharifi $M$, et al. Refinement of variant selection for the LDL cholesterol genetic risk score in the diagnosis of the polygenic form of clinical familial hypercholesterolemia and replication in samples from 6 countries. Clinical chemistry. 2015; 61(1):231-8. DOI: 10.1373/clinchem. 2014.231365 
6. de Ferranti SD, Rodday AM, Mendelson MM, Wong JB, Leslie LK, Sheldrick RC. Prevalence of familial hypercholesterolemia in the 1999 to 2012 United States national health and nutrition examination surveys (NHANES). Circulation. 2016; 133(11):106772.

7. Trenti C, Negri E, Leone M, Muoio A, Galimberti D, Pertinhez $\mathrm{T}$, et al. Use of evolocumab in a patient with homozygous familial hypercholesterolemia. Nutrition, Metabolism and Cardiovascular Diseases. 2017; 27(1):e40.DOI: https://doi.org/10.1016/j. numecd.2016.11.112.

8. Finegold JA, Manisty CH, Goldacre B, Barron AJ, Francis DP. What proportion of symptomatic side effects in patients taking statins are genuinely caused by the drug? Systematic review of randomized placebocontrolled trials to aid individual patient choice. European journal of preventive cardiology. 2014; $21(4): 464-74$.

9. Johnson KM, Dowe DA. Accuracy of statin assignment using the 2013 AHA/ACC Cholesterol Guideline versus the 2001 NCEP ATP III guideline: Correlation with atherosclerotic plaque imaging. Journal of the American College of Cardiology. 2014; 64(9):9109. https://doi.org/10.1016/j.jacc.2014.05.056

10. Sadeeqa S, Maqsood M, Ahmad M. Prevalence of statin induced myopathy in Lahore, Pakistan. Pakistan journal of pharmaceutical sciences. 2018; 31.

11. Xian-Yu J-B, Feng J-F, Chen Y-C, Yang Y-W. Effects of simvastatin and atorvastatin on biochemical and hematological markers in patients with risk of cardiovascular diseases. International journal of clinical and experimental medicine. 2015; 8(8):13983.
12. Sun K, D'Alessandro A, Xia Y. Purinergic control of red blood cell metabolism: novel strategies to improve red cell storage quality. Blood Transfusion. 2017;15(6):535.doi: 10.2450/2017.0366-16

13. Lichtenstein KA, Hart RL, Wood KC, Bozzette $S$, Buchacz K, Brooks JT, et al. Statin use is associated with incident diabetes mellitus among patients in the HIV outpatient study. Journal of acquired immune deficiency syndromes (1999). 2015;69(3):306.doi: 10.1097/QAI.0000000000000581.

14. Tahir S, Hayat A, Khan SA, Ahmad TM, Rehman S, Majeed $N$. Evaluation of chronic kidney disease patients for insulin resistance in tertiary care hospital. Pakistan Armed Forces Medical Journal. 2018(1):29-33.

15. Berry SA, Lichter-Konecki U, Diaz GA, McCandless SE, Rhead W, Smith W, et al. Glycerol phenylbutyrate treatment in children with urea cycle disorders: pooled analysis of short and long-term ammonia control and outcomes. Molecular genetics and metabolism. 2014; 112(1):17-24.DOI: https://doi. org/10.1016/j.ymgme. 2014.02.007.

16. Harada PH, Cook NR, Cohen DE, Paynter NP, Rose $\mathrm{L}$, Ridker PM. Relation of alanine aminotransferase levels to cardiovascular events and statin efficacy. American Journal of Cardiology. 2016; 118(1):49-55. DOI: $\quad$ https://doi.org/10.1016/j.amjcard.2016.04.012.

17. Broome S. Simon Broom 2018 [cited 2018 21-022018]. Available from: https://heartuk.org.uk/files/ uploads/documents/HUK_AS04_Diagnostic.pdf.

\begin{tabular}{|c|c|c|c|}
\hline \multicolumn{3}{|c|}{ AUTHORSHIP AND CONTRIBUTION DECLARATION } \\
\hline Sr. \# & Author(s) Full Name & \multicolumn{1}{|c|}{ Contribution to the paper } & Author(s) Signature \\
\hline 1 & Sufyan Tahir & $\begin{array}{l}\text { Conceived, designed, Data } \\
\text { collection final review. } \\
\text { Statistical analysis, manuscript } \\
\text { writing. }\end{array}$ \\
\hline 3 & Muhammad Usman & Hatiza Seerat Fatima & Datection, Editing. \\
\hline
\end{tabular}

